\title{
AVALIAÇÃO DE MICRORGANISMOS ANTAGÔNICOS, Saccharomyces cerevisiae E Bacillus subtilis PARA O CONTROLE DE Penicillium digitatum ${ }^{1}$
}

\author{
KATIA CRISTINA KUPPER ${ }^{2}$, ANTONIO LUCAS LIMA CERVANTES \\ MARIANA NADJARA KLEIN ${ }^{4}$, ALINE CAROLINE DA SILVA ${ }^{5}$
}

RESUMO - Os frutos cítricos são afetados por diversas doenças, especialmente as fúngicas, as quais afetam a produtividade e a qualidade, principalmente quando se visa ao mercado de frutas frescas, seja para o mercado interno, seja para a exportação. Dentre as doenças fúngicas que ocorrem na fase de pós-colheita, destacase o bolor verde, causado por Penicillium digitatum. As medidas de controle baseiam-se, principalmente, no tratamento de frutos com diferentes combinações de fungicidas no packing-house. Devido às restrições quanto à presença de resíduos de fungicidas em frutos de citros e ao crescente desenvolvimento de linhagens resistentes dos patógenos a tais fungicidas, torna-se necessária a busca de alternativas de controle, como o controle biológico. Portanto, este trabalho teve por objetivos: (i) verificar o efeito antagônico de agentes de controle biológico (ACBs), sendo 06 isolados de Saccharomyces cerevisiae e 13 isolados de Bacillus subtilis contra P. digitatum; (ii) estudar as interações in vitro entre ACBs e o fitopatógeno; (iii) verificar o efeito da integração dos antagonistas com bicarbonato de sódio e cera de carnaúba no controle do bolor verde. Os resultados mostraram que a maioria dos isolados bacterianos e todos os isolados de levedura inibiram o crescimento micelial do fitopatógeno. Somente um isolado de Bacillus subtilis (ACB-84) foi capaz de inibir a germinação de $P$. digitatum com $72 \%$ de inibição, enquanto ACB-K1 e ACB-CR1 (S. cerevisiae) foram os mais eficientes com inibições de 78 e 85,7\%, respectivamente; a adição de sacarose (a $0,5 \%$ ) favoreceu ainda mais a inibição da germinação dos conídios pelos isolados da levedura. Os resultados de controle in vivo mostraram a viabilidade de $S$. cerevisiae ACB-K1 e ACB-CR1 para o controle de $P$. digitatum, em frutos de lima-ácida 'Tahiti' e laranja 'Hamlin', respectivamente; a associação de bicarbonato de sódio com agentes de biocontrole não resultou em melhorias no controle curativo do bolor verde; cera de carnaúba (18\% de SST) favoreceu a atividade antagonística de $S$. cerevisiae, e tal efeito dependeu da variedade dos frutos cítricos em estudo e do isolado da levedura utilizado para o biocontrole.

Termos para indexação: bolor verde, Citrus spp., bicarbonato de sódio, cera de carnaúba.

\section{ASSESSMENT OF ANTAGONISTIC MICRO-ORGANISMS Saccharomyces cerevisiae AND Bacillus subtilis FOR CONTROLLING Penicillium digitatum}

ABSTRACT - Citrus fruits are affected by diverse diseases, mainly the fungal infections, which affect productivity and quality, especially when it targets the market of fresh fruit. Among the fungal diseases that occur in postharvest, there is the green mold caused by Penicillium digitatum. The control measures are based mainly in the treatment of fruits with different combinations of fungicides in packing-house. Due to restrictions on the presence of residues of fungicides in citrus fruits and the increasing development of resistant strains of pathogens to the fungicide used, it is necessary to search for control alternatives such as biological control. Therefore, this study aimed to: (i) verify the antagonistic effect of biological control agents (BCA), being 13 isolates of Bacillus subtilis and 06 isolates of Saccharomyces cerevisiae against $P$. digitatum, (ii) study in vitro interactions between pathogen and $\mathrm{BCA}$ (iii) determine the effect of integration of antagonists with sodium bicarbonate and carnauba wax in the control of green mold. The results showed that the majority of the isolates, and all yeast isolates inhibited the mycelial growth of the phytopathogen. Only one isolate of $B$. subtilis (ACB-84) was able to inhibit the germination of P. digitatum ( $72 \%$ of inhibition), whereas ACB-K1 and ACB- CR1 (S. cerevisiae) were the most effective with inhibition from 78 and $85.7 \%$ respectively. The addition of sucrose $(0.5 \%)$ favored the inhibition of conidia germination by the yeast isolates. The results from the in vivo control showed the viability of $S$. cerevisiae ACB-K1 and ACB-CR1 to control P. digitatum in 'Tahiti' lime fruits and orange 'Hamlin' fruits, respectively. The combination of sodium bicarbonate and biocontrol agents did not result in improvements in the curative control of the green mold. Carnauba wax (18\% of TSS) favored the antagonistic activity of S. cerevisiae, and this effect depended on the variety of fruits in the study and of the yeast isolate used for the biocontrol.

Index terms: green mold, Citrus spp., sodium bicarbonate, Carnaúba wax.

\footnotetext{
1(Trabalho 223-12) . Recebido em: 24-08-2012. Aceito para publicação em: 15-03-2013.

${ }^{2}$ Eng. Agr., Doutora, Pesquisadora do CCSM, IAC. , C. P. 04, Cordeirópolis-SP. E-mail: katia@centrodecitricultura.br ${ }^{3}$ Graduando do curso de Eng. agronômica (UFSCAR) Rod. Anhanguera, Km 174-Araras - SP. E-mail: tonycervantes@hotmail.com ${ }^{4}$ Bióloga, Doutoranda em Microbiologia Agropecuária (UNESP). Jaboticabal-SP. E-mail: mariana_klein28@hotmail.com ${ }^{5}$ Bióloga, Mestranda em Agroecologia e Desenvolvimento Rural (UFSCAR) Rod. Anhanguera, Km 174- Araras - SP. E-mail: line caroline@hotmail.com
} 


\section{INTRODUÇÃO}

O Brasil é o maior produtor mundial de laranja, respondendo por cerca de $30 \%$ da produção da fruta, $50 \%$ da produção de suco, com participação de $85 \%$ do suco comercializado internacionalmente (NEVES, 2010). O cultivo de espécies cítricas está assentado em uma área aproximada de $839 \mathrm{mil} \mathrm{hec-}$ tares, dos quais $77 \%$ se encontram localizados na região Sudeste do País. Cerca de $80 \%$ da produção de laranja no Estado de São Paulo é destinada à industrialização, cujo suco produzido é exportado para países como Rússia, Bélgica, Países Baixos, Estados Unidos e Japão, sendo os $20 \%$ restantes destinados ao consumo in natura, tanto para mercado interno como para exportação (AGRIANUAL, 2011).

Não obstante a importância econômica e social que representa a citricultura para o País, este setor enfrenta vários problemas de natureza fitossanitária. Dentre tais problemas, destacam-se as doenças de pós-colheita, que normalmente são iniciadas no campo e desenvolvem-se durante a colheita, transporte, embalagem e armazenamento.

As doenças que ocorrem na fase de pós-colheita diminuem a qualidade e a quantidade dos frutos cítricos, bem como prejudicam os valores nutricionais e de mercado. Dentre tais doenças, destaca-se o bolor verde dos frutos cítricos causado por Penicillium digitatum (Pers.: Fr) Sacc.

As medidas de controle atuais baseiam-se no tratamento de frutos com diferentes combinações de fungicidas em packing-house. Porém, dada a crescente restrição ao uso de fungicidas em pós-colheita, a demanda por produtos orgânicos e o problema com o desenvolvimento de linhagens resistentes aos produtos químicos (ZHU et al., 2006; KINAY et al., 2007), torna-se necessária a busca por produtos alternativos de controle.

Pesquisas recentes têm demonstrado a eficácia do controle biológico, através da ação de isolados de Bacillus subtilis e de leveduras no controle de doenças fúngicas em pós-colheita (LEELASUPHAKUL et al., 2008; CHANCHAOVIVAT et al., 2007).

No entanto, os agentes de biocontrole não podem fornecer por si sós a consistência e o amplo espectro de ação, se comparados aos fungicidas sintéticos. Em geral, micrororganismos antagonistas mostram grande variabilidade em sua eficácia, conferindo apenas efeito protetor que diminui com a maturação; normalmente, não podem erradicar infecções preexistentes ou incipientes e/ou não previnem esporulação de patógenos fúngicos (EL GHAOUTH et al., 2002). Uma das principais abordagens para melhorar o biocontrole de doenças de pós-colheita seria a integração com outros métodos:biológicos, químicos ou físicos (USALL et al., 2008)

A utilização de sais é uma prática muito comum na conservação de alimentos visando à preservação da longevidade de diferentes produtos. Dentre estes, o bicarbonato de sódio tem sido descrito na literatura como um produto que apresenta atividade antimicrobiana (YAO et al., 2004), reduzindo, inclusive, a incidência de bolores em frutos cítricos em pós-colheita (OBAGAWU; KORSTEN, 2003; CUNNINGHAM;TAVERNER, 2007).

A aplicação de cera em frutos, no processo de beneficiamento de pós-colheita, é utilizada para proteção contra danos que possam ocorrer durante o armazenamento em baixas temperaturas. A modificação da atmosfera ao redor dos frutos, com o uso de ceras, possibilita a formação de uma atmosfera modificada, retardando o processo de transpiração e a senescência, mantendo a firmeza e a turgescência das frutas, melhorando desta forma a qualidade visual. Além disso, alguns autores têm relatado que a cera apresenta ação antifúngica (reduzindo significativamente a incidência de podridões em frutos de ameixa, nectarina e citros) e minimiza desordens na casca e colapso do tecido (GONÇALVES, 2005).

Considerando o exposto, este trabalho teve por objetivos: (i) verificar o efeito antagônico de agentes de controle biológico (ACBs); (ii) estudar as interações in vitro entre $\mathrm{ACBs}$ e o fitopatógeno; (iii) verificar o efeito da integração dos antagonistas com bicarbonato de sódio e cera de carnaúba no controle do bolor verde.

\section{MATERIAL E MÉTODOS}

Para a realização deste trabalho, foram utilizados 13 isolados de Bacillus subtilis (ACB-12, ACB-15, ACB-16, ACB-69, ACB-70, ACB-72, ACB-73, ACB-77, ACB-82, ACB-83, ACB-84, ACB-85 e ACB-AP3) obtidos de flores e folhas (KUPPER;GIMENES-FERNANDES, 2002), 06 isolados de Saccharomyces cerevisiae (ACB-BG1, ACB-CAT1, ACB-CR1, ACB-K1, ACB-KD1 e ACB-PE2) doados pelo laboratório de Fitopatologia da Esalq-USP (Piracicaba- SP) e um isolado de Penicillium digitatum $(\mathrm{P}-23)$ pertencente à micoteca do centro Apta Citros "Sylvio Moreira"/IAC, Cordeirópolis-SP, Brasil.

Influência dos agentes de controle biológico (ACBs) no crescimento micelial de $\boldsymbol{P}$. digitatum - Para estudar o efeito antagônico dos agentes de controle biológico no crescimento micelial de $P$. 
digitatum, utilizou-se a técnica do cultivo pareado em placas de Petri, contendo batata-dextrose-ágar (BDA) (DENNIS; WEBSTER, 1971).

Discos de $5 \mathrm{~mm}$ de diâmetro, contendo colônias de B. subtilis ou de $S$. cerevisiae (ambos com dois dias de idade), foram transferidos para o centro das placas de Petri contendo BDA a $3 \mathrm{~cm}$ de distância da colônia do fitopatógeno. Para as testemunhas, foram repicadas colônias do patógeno sem o pareamento com os ACBs. A incubação das culturas deu se em ambiente de laboratório, e a avaliação ocorreu quando a cultura do patógeno atingiu toda a placa no tratamento-testemunha, pela medição das colônias dos fitopatógenos, em dois sentidos perpendiculares.

Seguiu-se um delineamento inteiramente casualizado, com cinco repetições, e as médias foram comparadas pelo teste de Tukey, a 5\% de probabilidade. Esse estudo foi realizado duas vezes.

Influência de isolados de agentes de controle biológico na germinação de $P$. digitatum. Este estudo compreendeu a realização de dois ensaios. No primeiro ensaio, alíquotas de $20 \mu \mathrm{L}$ de suspensão de cada um dos isolados de $B$. subtilis $\left(1 \times 10^{8}\right.$ $\mathrm{ufc} / \mathrm{mL})$ e de suspensão de conídios de $P$. digitatum $\left(1 \times 10^{4}\right.$ conídios $\left./ \mathrm{mL}\right)$ foram depositadas em áreas demarcadas de lâminas previamente preparadas, contendo meio ágar-água. O segundo ensaio, além de verificar o efeito dos isolados das leveduras sobre a germinação do fitopatógeno, estudou, também, a competição por nutrientes entre $P$. digitatum e $S$. cerevisiae. Para tal, diferentes concentrações $(0,5$; 1,$0 ; 1,5 ; 2,0$ e $2,5 \%$ ) de sacarose foram adicionadas em ágar-água. Alíquotas de $10 \mu \mathrm{L}$ de uma suspensão de $P$. digitatum $\left(1 \times 10^{5}\right.$ esporos $\left./ \mathrm{mL}\right)$ foram depositadas em áreas demarcadas de lâminas contendo meio agar-água com ou sem as diferentes concentrações de sacarose. Posteriormente, $10 \mu \mathrm{L}$ de suspensão, de cada um dos isolados da levedura $\left(1 \times 10^{8} \mathrm{ufc} / \mathrm{mL}\right)$, foram adicionadas, de acordo com os respectivos tratamentos. Para os tratamentos-testemunha dos dois ensaios, foram colocadas gotas de água destilada e esterilizada no lugar dos antagonistas. Depois de montadas as lâminas, as mesmas foram colocadas no interior de placas de Petri esterilizadas, contendo um chumaço de algodão embebido em água destilada e esterilizada. As culturas foram incubadas em estufa para $\mathrm{BOD}$, na temperatura de $25^{\circ} \mathrm{C}$, por 14 horas, no escuro. Ao término deste período, procedeu-se à avaliação, através da contagem de conídios germinados e não germinados, num total de 100 conídios, avaliados ao acaso, efetuando-se o cálculo da porcentagem de germinação de conídios de P. digitatum. Foi considerado germinado o conídio cujo tamanho do tubo germinativo se encontrava maior ou igual à largura do conídio. Antes da leitura, em cada lâmina, foram adicionados $10 \mu \mathrm{l}$ de uma solução contendo azul lático, com a finalidade de impedir o desenvolvimento do patógeno. Utilizou-se delineamento inteiramente casualizado, sendo cada tratamento composto por oito e 6 repetições, para os ensaios 1 e 2, respectivamente. As médias foram comparadas pelo teste de Tukey, a 5\% de probabilidade. Cada ensaio foi repetido duas vezes.

Integração de agentes de controle biológico com bicarbonato de sódio $\left(\mathrm{NaHCO}_{3}\right)$ e cera de carnaúba no controle de Penicillium digitatum Baseado nos resultados dos ensaios anteriores, um ensaio preliminar foi realizado com o objetivo de testar 2 isolados de B. subtilis (ACB-69 e ACB-84) e 2 isolados de $S$. cerevisiae (ACB-CR1 e ACB$-\mathrm{K} 1$ ), quanto à compatibilidade com bicarbonato de sódio, visando à possibilidade de um possível controle integrado. Para tal, $1 \mathrm{~mL}$ de bicarbonato de sódio, a uma concentração dez vezes superior à necessária, foi transferido para tubos de ensaio contendo $9 \mathrm{~mL}$ de cada uma das suspensões dos agentes de controle biológico $\left(10^{7} \mathrm{ufc} / \mathrm{ml}\right)$. A concentração final do sal foi de $2 \%$. Após a incubação por $30 \mathrm{~min}$ a $25^{\circ} \mathrm{C}$, as suspensões foram diluídas (10 vezes) em tampão fosfato a $0,05 \mathrm{M}(\mathrm{pH} 7) \mathrm{e}$, em seguida, repicadas para placas de Petri contendo BDA. As testemunhas constituíram-se de suspensões de células de cada ACB em água destilada e esterilizada, sem o sal. As culturas foram incubadas a $25^{\circ} \mathrm{C}$, no escuro, durante 24 horas. Cada tratamento foi repetido cinco vezes.

Posteriormente, foram conduzidos dois ensaios, um com frutos de lima-ácida 'Tahiti' e outro com frutos de laranjeira 'Hamlin', cujo objetivo foi avaliar o uso de ACBs (ACB-69, ACB-84, ACB-CR1 e ACB-K1), juntamente com $\mathrm{NaHCO}_{3}$, acondicionados à cera de carnaúba, nas concentrações de 12 e $18 \%$ de SST, visando a incrementar o controle do bolor verde dos frutos cítricos.

Para a multiplicação dos antagonistas, colônias foram transferidas para frascos de vidro com capacidade para $20 \mathrm{~L}$, contendo 15 litros de meio de cultura autoclavado a $120^{\circ} \mathrm{C}$, por 30 minutos, a $1 \mathrm{~atm}$. Os meios líquidos foram constituídos de batata-dextrose e de meio à base de adubo foliar, originário da fermentação glutâmica do melaço a $0,5 \%(\mathrm{v} / \mathrm{v})$, para a produção da levedura e da bactéria, respectivamente. Após a inoculação dos meios com os respectivos microorganismos, as culturas foram incubadas sob condições ambiente a $25^{\circ} \mathrm{C}\left( \pm 2^{\circ} \mathrm{C}\right)$, sob agitação constante, por 72 horas.

Foram utilizados os seguintes tratamentos: 
(i) frutos tratados com cada um dos ACBs (ACB-69, ACB-84, ACB-K1 e ACB-CR1); (ii) frutos tratados com $\mathrm{NaHCO}_{3}$; (iii) frutos tratados com $\mathrm{NaHCO}_{3}+$ ACBs; (iv) frutos tratados com cada um dos ACBs + cera a 12 e $18 \%$; (v) frutos tratados apenas com cera a 12 e $18 \%$; (vi) frutos tratados com $\mathrm{ACBs}+$ cera $(12$ ou $18 \%)+\mathrm{NaHCO}_{3}$; (vii) frutos tratados com $\mathrm{NaHCO}_{3}+$ cera (12 ou 18\%), (viii) frutos tratados com imazalil; (ix) frutos tratados com imazalil + cera (12 e 18\%) e, finalmente, (x) frutos inoculados e sem tratamento, totalizando, portanto, 34 tratamentos para cada variedade.

Frutos de lima-ácida 'Tahiti' ou de laranjeira 'Hamlin' foram lavados, esterilizados superficialmente com álcool a $75 \%$ e feridos em dois pontos equidistantes, na região equatorial, com estilete esterilizado, a uma profundidade de $3 \mathrm{~mm}$. Em seguida, os frutos foram inoculados com o fitopatógeno na concentração de $10^{5}$ esporos $/ \mathrm{mL}, 24$ horas antes da aplicação dos tratamentos. Os tratamentos com antagonistas foram aplicados pela imersão dos frutos por 2 minutos em solução aquosa contendo $1 \times 10^{8}$ ufc/ $\mathrm{mL}$. Com relação ao tratamento com o sal, os frutos foram imersos em uma solução de $\mathrm{NaHCO}_{3}$ a $2 \%$, durante 150 segundos (TEIXIDÓ et al., 2001). Para os tratamentos combinando $\mathrm{NaHCO}_{3}+$ antagonista + cera, primeiramente, os frutos foram imersos em $\mathrm{NaHCO}_{3}$ a 2\% (por 150 segundos), secados em laboratório e, em seguida, submetidos à imersão em caldo contendo $1 \times 10^{8} \mathrm{ufc} / \mathrm{mL}$ de cada $\mathrm{ACB}+$ cera, nas respectivas concentrações, seguindo o mesmo tempo descrito anteriormente.

Após a inoculação e os tratamentos, os frutos foram armazenados em temperatura ambiente a $27^{\circ} \mathrm{C}$ $\left( \pm 2^{\circ} \mathrm{C}\right) \operatorname{com} 70 \% \mathrm{UR}$.

Para cada ensaio, foi utilizado um delineamento inteiramente casualizado, com três repetições, sendo que cada repetição continha 15 frutos. A avaliação correspondeu à quantificação da porcentagem de

frutos sadios. Cada ensaio foi realizado duas vezes.

\section{RESULTADOS}

Influência dos agentes de controle biológico (ACBs) no crescimento micelial de $\boldsymbol{P}$. digitatum

Quando se observam os dados da Tabela 1, referentes aos tamanhos das colônias de $P$. digitatum, quando em cultivo pareado com os diferentes isolados bacterianos, nota-se que ACB-16, ACB-83, ACB-84, ACB-85, ACB-12, ACB-72, ACB-77 e ACB-70, em ordem crescente de eficiência, inibiram o crescimento do fungo, com valores de porcentagens de inibição que variaram entre 17,8 e 31,7\%, quando comparado com a testemunha.

Com relação ao efeito de $S$. cerevisiae sobre o crescimento micelial de P.digitatum (Figura 1), observa-se que, embora todos os isolados de levedura tenham afetado estatisticamente o desenvolvimento do fungo, ACB-CR1 e ACB-K1, quando comparados com a testemunha, apresentaram os melhores resultados, provocando inibições da colônia do fitopatógeno de $42 \%$ e $47 \%$, respectivamente.

Influência dos agentes de controle biológico na germinação de $\boldsymbol{P}$. digitatum

Os dados apresentados na Tabela 2 mostram que apenas o isolado bacteriano ACB-84 foi capaz de inibir a germinação de $P$. digitatum, diferindo estatisticamente da testemunha, com aproximadamente $72 \%$ de inibição.

Com relação aos dados referentes ao efeito dos isolados de $S$. cerevisiae na germinação de $P$. digitatum (Tabela 3), observa-se que ACB-K1 e ACB-CR1, quando avaliados sozinhos, ou seja, sem adição de sacarose, foram os que mais inibiram a germinação do patógeno, com valores de porcentagens de inibições de 78 e $85,7 \%$, respectivamente. Quando a menor concentração de sacarose $(0,5 \%)$, foi utilizada, esses dois isolados afetaram ainda mais a germinação de Penicillium. Com exceção do ACB-PE2, os demais isolados de levedura, quando na presença de sacarose (a $0,5 \%$ ) proporcionaram mais de $75 \%$ de inibição na germinação dos conídios de Penicillium. Concentrações de sacarose acima de $1,5 \%$ favoreceram a germinação do fitopatógeno.

Integração de agentes de controle biológico com bicarbonato de sódio e cera de carnaúba no controle de Penicillium digitatum

Os resultados do ensaio preliminar mostraram que todos os agentes de controle biológico foram compatíveis com o bicarbonato de sódio.

Os dados, referentes ao ensaio com frutos de lima-ácida 'Tahiti', tratados com a combinação de agentes de controle biológico com bicarbonato de sódio $\left(\mathrm{NaHCO}_{3}\right)$ e cera de carnaúba, em duas concentrações distintas (12 e 18\% SST), encontram-se na Tabela 4.

Os resultados demonstraram que os melhores tratamentos foram aqueles em que os frutos foram submetidos ao tratamento químico, com $100 \%$ de frutos sadios. Com relação às atividades dos agentes de biocontrole, verificou-se que o isolado ACBK1 (S. cerevisiae) e o isolado bacteriano ACB-84 foram os mais eficientes para o controle da doença, proporcionando, respectivamente, 62,22 e $53,33 \%$ de frutos sadios, enquanto os isolados ACB-CR1 e 
ACB-69 foram menos eficientes, proporcionando apenas 20 e $15,5 \%$ de frutos sem sintoma de bolor verde, respectivamente.

Por outro lado, quando o isolado de levedura ACB-CR1 foi combinado com cera a 12 e $18 \%$ SST , os tratamentos apresentaram 60 e $67 \%$ de frutos sadios, respectivamente.

Os piores níveis de controle foram obtidos quando os frutos de lima-ácida 'Tahiti' foram tratados com bicarbonato de sódio sozinho ou em combinação do sal mais cera, nas duas concentrações de sólido solúveis testadas, com $100 \%$ dos frutos doentes.

Com relação aos dados obtidos em frutos de laranjeira 'Hamlin' (Tabela 5), os resultados demonstraram que o melhor tratamento foi aquele em que os frutos foram submetidos ao tratamento com a levedura ACB-CR1 sozinha, proporcionando $87 \%$ de frutos sadios. Quando se utilizou a levedura associada ao bicarbonato de sódio, a porcentagem de controle diminuiu, apresentando $60 \%$ de frutos sem sintomas, não diferindo, inclusive, do tratamento com o sal sozinho, que proporcionou, também, $60 \%$ de frutos assintomáticos.

Um fato interessante a ser mencionado, foi que a levedura ACB-K1, que não foi tão eficiente quanto o isolado ACB-CR1 para o controle do bolor verde em frutos de laranjeira 'Hamlin', quando na associação do antagonista com bicarbonato de sódio + cera a $18 \%$ SST, mostrou melhoria na eficiência do controle, com uma quantidade de frutos sadios em torno de $71 \%$.

Os demais tratamentos e as respectivas combinações não se mostraram eficientes para o controle da doença em laranjeira 'Hamlin'.

\section{DISCUSSÃO}

Em vista do interesse na ampliação da exportação de frutas, o controle na armazenagem é imprescindível para garantir a qualidade do produto. Consumidores do mercado externo estão cada vez mais preocupados e impondo exigências no que diz respeito à aquisição de frutas isentas de resíduos de agrotóxicos. O uso de microorganismos como agentes de controle biológico para doenças de pós-colheita constitui-se numa alternativa viável em todo o mundo, principalmente pelo fato de não deixarem resíduos nos frutos (SHARMA et al., 2009).

Sob o ponto de vista de segurança alimentar, um aspecto a ser considerado trata-se da possibilidade de agentes de biocontrole que, ao apresentarem a antibiose como um de seus mecanismos de ação, poderia deixar algum resíduo em frutos para consumo in natura. Em vista dessa situação, abre-se a pers- pectiva do emprego de levedura para o biocontrole, devido, principalmente, à baixa possibilidade micotoxigênica deste grupo de microrganismo, grandemente utilizado em muitos processos fermentativos. Diante do exposto, os resultados apresentados, neste estudo, mostraram que os isolados de $S$. cerevisiae (ACB-K1 e ACB-CR1) reduziram significativamente a incidência do bolor verde, quando frutos de lima-ácida 'Tahiti' e laranjeira 'Hamlin' foram inoculados artificialmente, apresentando uma eficiência de controle maior que os isolados bacterianos. No entanto, os antagonistas não foram tão efetivos quanto o tratamento químico, que apresentou controle total da doença.

O que se pode observar neste trabalho é que a atividade de controle dos agentes de biocontrole testados dependeu das características fisiológicas das variedades dos frutos cítricos, ou seja, o tratamento dos frutos com o isolado ACB-K1 foi melhor para o controle da doença em lima-ácida 'Tahiti' ( $62 \%$ de controle), enquanto o isolado ACB-CR1 teve melhor desempenho no controle de Penicillium em frutos de laranjeira 'Hamlin', proporcionando $87 \%$ de frutos assintomáticos.

Por outro lado, o uso de bicarbonato de sódio sozinho ou em combinação com os agentes de biocontrole não resultou em melhorias no controle da doença em frutos de lima- ácida 'Tahiti'. Com exceção do isolado bacteriano ACB-69 em combinação com o sal, que proporcionou $40 \%$ de frutos sadios, os demais microrganismos na combinação apresentaram baixa eficiência de controle (de 8,89 a 13,33\%). No entanto, quando frutos de laranjeira 'Hamlin' foram tratados com o sal sozinho ou em combinação com o isolado de $S$. cerevisiae ACB-CR1, a eficiência de controle foi de $60 \%$ de frutos sadios.

A baixa eficiência do sal apresentada neste estudo foi inesperada, quando comparada com outros trabalhos de literatura. Os efeitos de sais de carbonatos e outros aditivos, de baixa toxicidade ou compostos denominados GRAS, contra uma variedade de patógenos de pós-colheita, incluindo, $P$. digitatum, são conhecidos por terem uma ação fungistática e serem pouco persistentes (PALOU et al., 2002). Segundo Obagawu e Korsten (2003), houve aumento significativo na atividade antagonística de diferentes isolados de B. subtilis, quando os mesmo foram combinados com bicarbonato de sódio, durante o biocontrole de $P$. digitatum em frutos de laranjeira Valência e Shamouti. Para Usall et al. (2008), laranjas previamente tratadas com soluções aquecidas $\left(40^{\circ} \mathrm{C}\right)$ de bicarbonato de sódio (3\%), seguido pela aplicação de suspensão de Pantoea agglomerans, apresentou total controle do bolor verde.

Os dados divergentes obtidos em nosso 
estudo talvez possam ser explicados considerando-se dois fatores: primeiramente, o fato de ter sido utilizada menor concentração do sal $(2 \%)$, o que poderia ter afetado a eficiência de controle do tratamento; segundo, pelo fato de os tratamentos terem sido realizados de forma curativa, e, neste aspecto, talvez os mesmos não tenham conseguido atingir o patógeno no momento em que ele se encontrava mais frágil e exposto, ou seja, durante a germinação de seus conídios; de modo que, quando os frutos receberam os tratamentos, o patógeno já se encontrava estabelecido. De acordo com Conway et al. (2004), os conídios germinados são mais suscetíveis à ação do sal.

É importante mencionar que os trabalhos relatados acima se referem a resultados efetivos de controle da doença pela utilização da combinação do sal com agentes de biocontrole em frutos de laranja. Quando se observam os resultados apresentados neste trabalho, embora tenha sido obtida uma eficiência menor de controle $(60 \%)$, quando os frutos de laranja 'Hamlin' foram tratados com bicarbonato de sódio + ACB-CR1, em comparação ao controle obtido com a levedura sozinha (87\%), mesmo assim, o controle foi superior ao apresentado pelo mesmo tratamento aplicado em frutos de lima-ácida Tahiti.

Os dados que envolveram a utilização dos isolados de levedura, combinados com bicarbonato de sódio e cera de carnaúba, indicaram que uma concentração maior de cera $(18 \% \mathrm{SST})$ favoreceu a atividade antagonística do isolado ACB-K1, quando combinado com o sal em frutos de laranjeira 'Hamlin, proporcionando $71 \%$ de frutos sadios (Tabela 5). Considerando que o tratamento onde se combinou cera a $18 \%+\mathrm{NaHCO}_{3}$ tenha favorecido o controle (com 67\% de frutos sadios) em comparação ao tratamento no qual os frutos foram tratados apenas com o sal ( $60 \%$ de controle), acredita-se que o sinergismo entre o bicarbonato, o sal e a levedura ACB-K1 tenha favorecido o controle.

Tal efeito também foi observado para o isolado ACB-CR1, porém, quando se utilizou apenas a cera $(18 \% \mathrm{SST})$, ou seja, sem associação com sal, promovendo uma eficiência de controle de $67 \%$ de frutos sadios em lima-ácida 'Tahiti' (Tabela 4).

Considerando os dados dos dois ensaios, pode-se afirmar que cera, principalmente a $18 \%$ de SST, afeta a atividade antagonística das leveduras, e tal efeito depende da variedade dos frutos cítricos em estudo. Enquanto ACK-K1 e ACB-CR1 se mostram eficientes no controle da doença em frutos de lima-ácida 'Tahiti' e laranjeira 'Hamlin', respectivamente, quando em associação com a cera nessa concentração ( $18 \%$ de SST), ocorre uma inversão de eficiência de controle por parte dos isolados da levedura dentro de cada variedade dos frutos.

Pela facilidade de controle, se for considerada a formulação de um produto biológico com apenas um isolado de levedura para controle de bolor verde que possa ser aplicado tanto para frutos de laranja como de lima-ácida Tahiti, a utilização de cera durante o beneficiamento seria uma alternativa indispensável; no entanto, mais estudos devem ser realizados. Ainda com relação à ação da cera na inibição de doenças na fase de pós-colheita, Gonçalves (2005) demonstrou que o uso de cera de carnaúba ( $9 \%$ SST) reduziu, significativamente, a incidência de podridão-parda (Monilinia fructicola) e podridão-mole (Rhizopus stolonifer), quando frutos de ameixa e nectarina foram tratados preventivamente antes de serem inoculados artificialmente.

Independentemente dos diversos métodos de controle do bolor verde abordados neste estudo, o modo de ação apresentado pelos isolados de $S$. cerevisiae, em especial ACB-K1 e ACB-CR1, contra $P$. digitatum em frutos cítricos, pode explicar a limitada atividade curativa dos antagonistas aplicados sozinhos ou em combinação com bicarbonato de sódio ou cera. $\mathrm{O}$ efeito inibitório, devido à competição por nutrientes e espaço, é consideravelmente mais baixo quando a levedura é aplicada após a inoculação do patógeno que já está estabelecido e crescendo ativamente no sítio de infecção. Considerando que, com exceção do ACB-PE2, os demais isolados de levedura, quando na presença de sacarose (a $0,5 \%$ ), proporcionaram mais de $75 \%$ de inibição na germinação dos conídios de Penicillium, acredita-se que a competição por nutrientes é, realmente, um dos mecanismos de ação envolvido no antagonismo.

Portanto, em estudos posteriores, seria importante que as leveduras ACB-K1 e ACB-CR1 fossem testadas de forma preventiva no controle do bolor verde, em frutos de lima- ácida Tahiti e de laranja, respectivamente. 
TABELA 1- Efeito de isolados de Bacillus subtilis no crescimento micelial de Penicillium digitatum avaliado por meio da técnica de cultivo pareado.

\begin{tabular}{lcc}
\hline \multicolumn{1}{c}{ Isolado } & $\begin{array}{c}\text { Tamanho da colônia de } \\
P \text {. digitatum }(\mathrm{cm})\end{array}$ & $\begin{array}{c}\text { Porcentagem de inibição em } \\
\text { relação à testemunha }\end{array}$ \\
Testemunha & $2,05 \mathrm{a}^{(1)}$ & 6,3 \\
ACB-82 & $1,92 \mathrm{ab}$ & 10,2 \\
ACB-AP3 & $1,84 \mathrm{abc}$ & 12,7 \\
ACB-69 & $1,79 \mathrm{abcd}$ & 14,2 \\
ACB-73 & $1,76 \mathrm{abcd}$ & 15,1 \\
ACB-15 & $1,74 \mathrm{abcde}$ & 17,6 \\
ACB-16 & $1,69 \mathrm{bcde}$ & 20,0 \\
ACB-83 & $1,64 \mathrm{bcde}$ & 22,4 \\
ACB-84 & $1,59 \mathrm{bcde}$ & 23,9 \\
ACB-85 & $1,56 \mathrm{cde}$ & 26,3 \\
ACB-12 & 1,51 cde & 26,8 \\
ACB-72 & 1,50 de & 31,2 \\
ACB-77 & $1,41 \quad \mathrm{e}$ & 31,7 \\
ACB-70 & $1,40 \quad \mathrm{e}$ & \\
\hline
\end{tabular}

${ }^{(1)}$ Médias seguidas pela mesma letra não diferem entre si, pelo teste de Tukey, a 5\% de probabilidade. Análise efetuada com os dados transformados em $(\mathrm{x}+0,5)^{1 / 2}$.

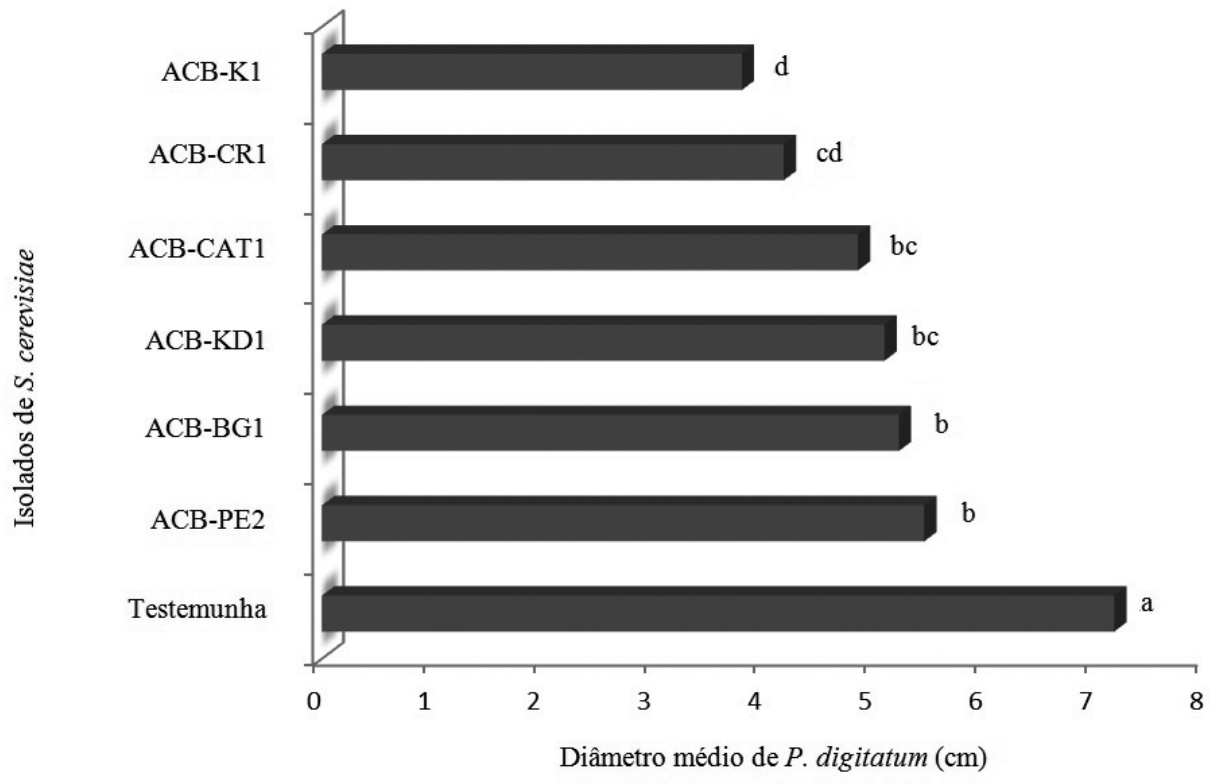

FIGURA 1- Efeito de isolados de Saccharomyces cerevisiae no crescimento micelial de Penicillium digitatum, avaliado por meio da técnica de cultivo pareado.

Médias seguidas pela mesma letra não diferem entre si, pelo teste de Tukey, a 5\% de probabilidade. 
TABELA 2 - Efeito de isolados de Bacillus subtilis na germinação de conídios de Penicillium digitatum em meio ágar-água, após 14 horas de incubação a 25ํㅡ.

\begin{tabular}{ccc}
\hline Isolado & Porcentagem de germinação Porcentagem de inibição em relação à testemunha \\
\hline ACB-76 & $57,8 \mathrm{a}^{(1)}$ & $-12,3$ \\
ACB-16 & $54,3 \mathrm{ab}$ & $-5,5$ \\
Testemunha & $51,5 \mathrm{abc}$ & - \\
ACB-85 & $51,2 \mathrm{abc}$ & 0,6 \\
ACB-12 & $49,8 \mathrm{abc}$ & 3,3 \\
ACB-AP3 & $49,3 \mathrm{abc}$ & 4,3 \\
ACB-72 & $47,5 \mathrm{abc}$ & 7,8 \\
ACB-70 & $45,6 \mathrm{abc}$ & 11,4 \\
ACB-77 & $44,0 \mathrm{abc}$ & 14,6 \\
ACB-15 & $43,7 \mathrm{abc}$ & 15,1 \\
ACB-73 & $43,2 \mathrm{abc}$ & 16,2 \\
ACB-83 & $38,9 \mathrm{bc}$ & 24,5 \\
ACB-82 & $38,7 \mathrm{bc}$ & 24,9 \\
ACB-69 & $37,6 \mathrm{c}$ & 27,1 \\
ACB-84 & $14,6 \mathrm{~d}$ & 71,7 \\
\hline
\end{tabular}

${ }^{1}$ Médias seguidas pela mesma letra não diferem entre si, pelo teste de Tukey, a 5\% de probabilidade. Análise efetuada com os dados transformados em $\operatorname{arcsen}(\mathrm{x}+0,5)^{1 / 2}$.

TABELA 3- Efeito de isolados de Saccharomyces cerevisiae na germinação de conídios de Penicillium digitatum, em meio ágar-água, acrescido ou não com diferentes concentrações de sacarose $(0,5 ; 1 ; 1,5 ; 2$ e $2,5 \%)$.

\begin{tabular}{|c|c|c|c|c|c|}
\hline Tratamento & Sacarose $(\%)$ & \% de Germinação & Tratamento & Sacarose (\%) & \% de Germinação \\
\hline ACB-PE2 & 2,5 & $97,6 \mathrm{a}$ & Testemunha & 1,0 & $52,8 \mathrm{f}$ \\
\hline Testemunha & 2,5 & $92,3 \mathrm{a}$ & ACB-CR1 & 1,5 & $52,0 \mathrm{f}$ \\
\hline ACB-PE2 & 2,0 & $90,5 \mathrm{a}$ & ACB-CAT1 & 0,0 & $50,1 \mathrm{~g}$ \\
\hline ACB-CR-1 & 2,5 & $88,3 \mathrm{~b}$ & ACB-BG1 & 0,0 & $50,0 \mathrm{~g}$ \\
\hline ACB-K1 & 2,5 & $86,5 \mathrm{~b}$ & ACB-KD1 & 0,0 & $49,5 \mathrm{~g}$ \\
\hline ACB-PE2 & 1,5 & $86,0 \mathrm{~b}$ & ACB-KD1 & 1,5 & $48,8 \mathrm{~g}$ \\
\hline ACB-CAT1 & 2,5 & $84,5 \mathrm{~b}$ & Testemunha & 0,5 & $47,0 \mathrm{~g}$ \\
\hline ACB-PE2 & 1,0 & $81,5 \mathrm{~b}$ & ACB-KD1 & 1,0 & $45,3 \mathrm{~g}$ \\
\hline Testemunha & 2,0 & $76,0 \mathrm{c}$ & ACB-K1 & 1,0 & $39,3 \mathrm{~h}$ \\
\hline ACB-K1 & 2,0 & $74,8 \mathrm{c}$ & ACB-BG1 & 2,0 & $37,3 \mathrm{~h}$ \\
\hline ACB-PE2 & 0,5 & $73,5 \mathrm{c}$ & ACB-CAT1 & 1,0 & $29,5 \mathrm{i}$ \\
\hline ACB-BG1 & 2,5 & $72,3 \mathrm{~d}$ & ACB-BG1 & 1,5 & $27,0 \quad \mathrm{i}$ \\
\hline ACB-CR1 & 2,0 & $71,0 \mathrm{~d}$ & ACB-KD & 0,5 & $25,5 \quad \mathrm{j}$ \\
\hline ACB-PE2 & 0,0 & $69,0 \mathrm{~d}$ & ACB-CR1 & 1,0 & $24,0 \quad j$ \\
\hline ACB-CAT1 & 2,0 & 65,0 e & ACB-K1 & 0,0 & $22,0 \quad \mathrm{j}$ \\
\hline Testemunha & 1,5 & 64,1 e & ACB-CAT1 & 0,5 & 16,1 \\
\hline ACB-KD1 & 2,5 & 61,1 e & ACB-CR1 & 0,0 & 14,3 \\
\hline ACB-K1 & 1,5 & $56,1 \quad \mathrm{f}$ & ACB-BG1 & 1,0 & 14,0 \\
\hline ACB-KD1 & 2,0 & $54,6 \mathrm{f}$ & ACB-K1 & 0,5 & 12,8 \\
\hline ACB-CAT1 & 1,5 & $53,6 \quad f$ & ACB-CR1 & 0,5 & 10,3 \\
\hline Testemunha & 0,0 & $53,5 \mathrm{f}$ & ACB-BG1 & 0,5 & 9,1 \\
\hline
\end{tabular}

Médias seguidas pela mesma letra não diferem entre si pelo Teste de Scott-Knott a 5\%. 
TABELA 4 - Integração de agentes de controle biológico com bicarbonato de sódio $\left(\mathrm{NaHCO}_{3}\right)$ e cera de carnaúba (12 e 18\% Sólido Solúveis Totais) no controle de Penicillium digitatum, em limaácida 'Tahiti'.

\begin{tabular}{|c|c|}
\hline Tratamentos & $\%$ frutos sadios \\
\hline Imazalil & $100,0 \mathrm{a}$ \\
\hline Imazalil + Cera $12 \%$ & $100,0 \mathrm{a}$ \\
\hline Imazalil + Cera 18\% & $100,0 \mathrm{a}$ \\
\hline Test. sem inoculação & $100,0 \mathrm{a}$ \\
\hline ACB-CR $1+$ Cera $18 \%$ & $66,7 \mathrm{~b}$ \\
\hline ACB-K1 & $62,2 \mathrm{c}$ \\
\hline ACB-CR $1+$ Cera $12 \%$ & $60,0 \mathrm{c}$ \\
\hline Cera $18 \%$ & $53,3 \mathrm{~d}$ \\
\hline ACB-84 & $53,3 \mathrm{~d}$ \\
\hline ACB- $84+$ Cera $18 \%+\mathrm{NaHCO}_{3}$ & $44,4 \mathrm{e}$ \\
\hline $\mathrm{ACB}-69+\mathrm{NaHCO}_{3}$ & $40,0 \mathrm{f}$ \\
\hline ACB-K1+Cera $18 \%$ & $40,0 \mathrm{f}$ \\
\hline ACB-K1+Cera $12 \%$ & $28,9 \mathrm{~g}$ \\
\hline ACB- $84+$ Cera $12 \%$ & $24,4 \mathrm{~h}$ \\
\hline ACB- $84+$ Cera $12 \%+\mathrm{NaHCO}_{3}$ & $20,0 \mathrm{i}$ \\
\hline ACB- $84+$ Cera $18 \%$ & $20,0 \mathrm{i}$ \\
\hline ACB-CR1 & $20,0 \mathrm{i}$ \\
\hline ACB-K1+Cera $18 \%+\mathrm{NaHCO}_{3}$ & $20,0 \mathrm{i}$ \\
\hline ACB-69 & $15,6 \mathrm{j}$ \\
\hline ACB- $69+$ Cera $12 \%$ & $15,6 \mathrm{j}$ \\
\hline Testem.Inoculada & $15,6 \mathrm{j}$ \\
\hline Cera $12 \%$ & $15,6 \mathrm{j}$ \\
\hline ACB- $69+$ Cera $18 \%$ & $13,3 \mathrm{jl}$ \\
\hline $\mathrm{ACB}-\mathrm{K} 1+\mathrm{NaHCO}_{3}$ & $13,3 \mathrm{jl}$ \\
\hline ACB-CR $1+$ Cera $12 \%+\mathrm{NaHCO}_{3}$ & $13,3 \mathrm{jl}$ \\
\hline $\mathrm{ACB}-\mathrm{CR} 1+\mathrm{NaHCO}_{3}$ & $13,3 \mathrm{jl}$ \\
\hline ACB- $69+$ Cera $12 \%+\mathrm{NaHCO}_{3}$ & $11,1 \mathrm{~lm}$ \\
\hline ACB-69 + Cera $18 \%+\mathrm{NaHCO}_{3}$ & $11,1 \mathrm{~lm}$ \\
\hline ACB-K1+Cera $12 \%+\mathrm{NaHCO}_{3}$ & $11,1 \mathrm{~lm}$ \\
\hline ACB-CR $1+\mathrm{Cera} 18 \%+\mathrm{NaHCO}_{3}$ & $11,1 \mathrm{~lm}$ \\
\hline $\mathrm{ACB}-84+\mathrm{NaHCO}_{3}$ & $8,9 \mathrm{~m}$ \\
\hline Cera $12 \%+\mathrm{NaHCO}_{3}$ & $0,0 \mathrm{n}$ \\
\hline Cera $18 \%+\mathrm{NaHCO}_{3}$ & $0,0 \mathrm{n}$ \\
\hline $\mathrm{NaHCO}_{3}$ & $0,0 \mathrm{n}$ \\
\hline
\end{tabular}

Médias seguidas pela mesma letra não diferem entre si, pelo teste de Tukey, a 5\% de probabilidade. 
TABELA 5- Integração de agentes de controle biológico com bicarbonato de sódio $\left(\mathrm{NaHCO}_{3}\right)$ e cera de carnaúba (12 e 18\% Sólido Solúveis Totais) no controle de Penicillium digitatum, em laranjeira 'Hamlin'.

\begin{tabular}{|c|c|}
\hline Tratamentos & $\%$ frutos sadios \\
\hline Imazalil & $100,0 \mathrm{a}$ \\
\hline Imazalil+Cera $12 \%$ & $100,0 \mathrm{a}$ \\
\hline Imazalil+Cera $18 \%$ & $100,0 \mathrm{a}$ \\
\hline Test. sem inoculação & $100,0 \mathrm{a}$ \\
\hline ACB-CR1 & $86,7 \mathrm{~b}$ \\
\hline ACB-K1+Cera $18 \%+\mathrm{NaHCO}_{3}$ & $71,1 \mathrm{c}$ \\
\hline Cera $18 \%+\mathrm{NaHCO}_{3}$ & $66,7 \mathrm{~d}$ \\
\hline $\mathrm{ACB}-\mathrm{CR} 1+\mathrm{NaHCO}_{3}$ & 60,0 e \\
\hline $\mathrm{NaHCO}_{3}$ & 60,0 e \\
\hline ACB- $84+$ Cera $18 \%+\mathrm{NaHCO}_{3}$ & $53,3 \mathrm{f}$ \\
\hline Cera $12 \%+\mathrm{NaHCO}_{3}$ & $46,7 \mathrm{~g}$ \\
\hline ACB-CR $1+\mathrm{Ce} a 18 \%+\mathrm{NaHCO}_{3}$ & $40,0 \mathrm{~h}$ \\
\hline ACB-69 + Cera $18 \%+\mathrm{NaHCO}_{3}$ & $33,3 \mathrm{i}$ \\
\hline ACB-84 & $22,2 \mathrm{j}$ \\
\hline $\mathrm{ACB}-\mathrm{K} 1+\mathrm{NaHCO}_{3}$ & 17,81 \\
\hline ACB-K1+Cera $12 \%+\mathrm{NaHCO}_{3}$ & $13,3 \mathrm{~m}$ \\
\hline $\mathrm{ACB}-\mathrm{CR} 1+\mathrm{Cera} 12 \%+\mathrm{NaHCO}_{3}$ & $13,3 \mathrm{~m}$ \\
\hline Cera $12 \%$ & $11,1 \mathrm{~m}$ \\
\hline ACB-K1+Cera $12 \%$ & $11,1 \mathrm{~m}$ \\
\hline ACB-K1 & $11,1 \mathrm{~m}$ \\
\hline ACB-69 + $\mathrm{NaHCO}_{3}$ & $6,7 \mathrm{n}$ \\
\hline ACB-84 + $\mathrm{NaHCO}_{3}$ & $6,7 \mathrm{n}$ \\
\hline ACB- $84+$ Cera $12 \%$ & 4,4 no \\
\hline ACB-CR $1+$ Cera $12 \%$ & 2,2 o \\
\hline ACB- $84+$ Cera $12 \%+\mathrm{NaHCO}_{3}$ & 2,2 o \\
\hline ACB-69 & 2,20 \\
\hline Test. Inoculada & 2,2 o \\
\hline ACB-CR $1+$ Cera $18 \%$ & $0 \mathrm{p}$ \\
\hline Cera $18 \%$ & $0 \mathrm{p}$ \\
\hline ACB-K $1+$ Cera $18 \%$ & $0 \mathrm{p}$ \\
\hline ACB- $84+$ Cera $18 \%$ & $0 \mathrm{p}$ \\
\hline ACB-69 + Cera $12 \%$ & $0 \mathrm{p}$ \\
\hline ACB-69 + Cera $18 \%$ & $0 \mathrm{p}$ \\
\hline ACB- $69+$ Cera $12 \%+\mathrm{NaHCO}_{3}$ & $0 \mathrm{p}$ \\
\hline
\end{tabular}

* Médias seguidas pela mesma letra não diferem entre si, pelo teste de Tukey, a 5\% de probabilidade. 


\section{CONCLUSÕES}

Pelos resultados obtidos, pode-se concluir que:

1- É viável o uso de Saccharomyces cerevisiae para o controle de Penicillium digitatum, porém a eficiência de antagonismo do isolado depende da variedade cítrica que está sendo tratada.

2- A associação de bicarbonato de sódio com agentes de biocontrole não resulta em melhorias no controle curativo do bolor verde.

3- Cera de carnaúba ( $18 \%$ de SST) favorece a atividade antagonistica de $S$. cerevisiae, e tal efeito depende da variedade dos frutos cítricos em estudo e do isolado da levedura utilizado para o biocontrole.

\section{AGRADECIMENTOS}

À Fundação de Amparo à Pesquisa do Estado de São Paulo -FAPESP, pelo suporte financeiro (Processo n. 2007/03692-0).

\section{REFERÊNCIAS}

AGRIANUAL: anuário da agricultura Brasileira. São Paulo: FNP, 2011. p. 245-306.

CHANCHAICHAOVIVAT, A.; RUENWONGSA, P.; PANIJPAN, B. Screening and identification of yeast strains from fruits and vegetables: Potential for biological control of postharvest chilli anthracnose (Colletotrichum capsici). Biological Control, San Diego, v. 42, p. 326-335, 2007.

CONWAY, W. S.; LEVERENTZ, B.; JANISIEWICZ, W.J.; BLODGETT, A.B.; SAFTNER, R.A.; CAMP, M.J. Integrating heat treatment, biocontrol and sodium bicarbonate to reduce postharvest decay of apple caused by Colletotrichum acutatum and Penicillium expansum. Postharvest Biology and Technology, Pullman, v. 34, p. 11-20, 2004.

CUNNINGHAM, N.M.; TAVERNER, P.D. Efficacy of integrated postharvest treatments against mixed innoculations of Penicillium digitatum and Geotrichum citri-aurantii in 'Leng' navel oranges (Citrus sinensis). New Zealand Journal of Crop and Horticultural Science, Nova Zelandia, v. 35, p. 187-192, 2007.

DENNIS, C.; WEBSTER, J. Antagonists porperties of species groups of Trichoderma III. Hyphal interactions. Transactions of the British Mycological Society, London, v.57, p.359-363, 1971.
EL GHAOUTH, A.; WILSON, C.L.; WISNIEWSKI, M.; DROBY,S.; SMILANICK, J.L.; KORSTEN, L. Biological control of postharvest diseases of citrus fruits. In: GNANAMANICKAM, S.S. (Ed.). Biological control of crop diseases. New York: Marcel Dekker, 2002. p.289-312.

GONÇALVES F. P. Quantificação de danos e controle pós-colheita de podridões parda (Monilinia fructicola) e podridão mole (Rhizopus stolonifer) em frutos de ameixa e nectarina. Piracicaba: Universidade de São Paulo, 2005. p.73.

KINAY, P.; MANSOUR, M.F.; GABLER, F. M.; MARGOSAN, D. A.; SMILANICK, J. L. Characterization of fungicide-resistant isolates of Penicillium digitatum collected in California. Crop Protection, Amsterdam, v. 26, p. 647-656, 2007.

KUPPER K.C.; GIMENES-FERNANDES, N. Isolamento e seleção de Bacillus spp. para o controle de Colletotrichum acutatum em flores destacadas de lima ácida "Tahiti". Summa Phytopathologica, Jaboticabal, v. 28, p.292-295, 2002.

LEELASUPHAKUL W.; HEMMANEEA P.; CHUENCHITT S. Growth inhibitory properties of Bacillus subtilis strains and their metabolites against the green mold pathogen (Penicillium digitatum Sacc.) of citrus fruit. Postharvest Biology and Technology, Pullman, v. 48, p.113-121, 2008.

NEVES, M.F. O retrato da citricultura brasileira. Ribeirão Preto: FEA/USP, 2010. p.137.

OBAGWU, J.; KORSTEN, L. Integrated control of citrus green and blue mold using Bacillus subtilis in combination with sodium bicarbonate or hot water. Postharvest Biology and Technology, Pullman, v. 28, p.187-194. 2003.

PALOU, L.; USALL, J.; MUNÕZ, J.A.; SMILANICK, J.L.; VINÃS, I. Hot water, sodium carbonate, and sodium bicarbonate for the control of postharvest green and blue molds of clementine mandarins. Postharvest Biology and Technology, Pullman, v. 24, p.93-96, 2002.

SHARMA, R.R.; SINGH, D.; SINGH, R. Biological control of postharvest diseases of fruits and vegetables by microbial antagonists: A review. Biological Control, San Diego, v.50, n.3, p.205221, 2009. 
TEIXIDÓ, N.; USALL, J.; PALOU, L.; ASENSIO, A.; NUNES, C.; VINÃS, I. Improving control of green and blue molds of oranges by combining Pantoe agglomerans (CPA-2) and sodium bicarbonate. European Journal of Plant Pathology, Amsterdam, v.107, p. 685-694, 2001.

USALL, J.; SMILANICK, J.; PALOU, L.; DENISARRUE, N.; TEIXIDÓ, N.; TORRES, R.; VIÑAS, I. Preventive and curative activity of combined treatments of sodium carbonates and Pantoea agglomerans CPA-2 to control postharvest green mold of citrus fruit. Postharvest Biology and Technology, Pullman, v. 50, p.1-7, 2008.
YAO, H.; TIAN, S.; WANG, Y. Sodium bicarbonate enhances biocontrol efficacy of yeasts on fungal spoilage of pears. International Journal of Food Microbiology, Torino, v.93, p.297-304, 2004.

ZHU, J.; XIE, Q.; LI, H. Occurrence of imazalilresistant biotype of Penicillium digitatum in China and the resistant molecular mechanism. Journal of Zhejiang University SCIENCE A, Zhejiang, v.7, n.2, p. 362-365, 2006. Suplemento. 